\title{
Punishment-induced facilitation: Comments and analysis
}

\author{
R. CHRIS MARTIN, HOLLINS COLLEGE \\ KENNETH B. MELVIN, UNIVERSITY OF ALABAMA
}

A theoretical and methodological analysis of recent research (e.g., Smith, Misanin, \& Campbell, 1966) was done in order to reconcile some divergent results. Varied effects of punishment of escape and avoidance responses were attributed, in large degree, to the location of punishment in the response sequence.

In a recent article in this journal, Smith, Misanin, \& Campbell (1966) reported that punishment inhibited avoidance behavior. Inhibition was found even though their study was "...designed to maximize the possibilities of obtaining facilitation curing extinction." The question of possible facilitative effects of punishment, according to Smith et al, stems from the "vicious circle" hypothesis of Mowrer (1960). Since punishment-induced facilitation has been reported in several recent studies (e.g., Hurwitz, 1961; Brown, Martin, \& Morrow, 1964; Melvin, 1964; Brown, Anderson, \& Weiss, 1965), a comparison of procedures might reveal the reasons for these divergent results.

An examination of Mowrer's vicious circle hypothesis reveals that it is relevant to a different procedure from that used by Smith et al. The vicious circle phenomenon is observed in the following paradigm: After rats have learned to traverse a runway to avoid or escape shock, their responses are more persistent when a section of the runway, but not the start box or goal box, is electrified than when it is not (Mowrer, 1960; Brown et al, 1964). Mowrer holds that in punishment-extinction the fear conditioned to the shock end of the runway readily generalizes to the beginning end, thus motivating continued starting and running. Smith et al used a two-way shuttle situation in which the rat was punished when he pushed through a swinging door and entered another compartment.

There are several important differences between the typical vicious circle situation and that used by Smith et al. Perhaps the most important of these is that Smith et al applied punishment after the response and in the "goal box" (which was also the "start box"). In the vicious circle paradigm, however, the punishment is introduced in an intermediate section of a response chain.

Smith et al also stated that, according to Mowrer (1960), Solomon, Kamin, \& Wynne (1953) and Church (1963), "...punishment is more likely to facilitate behavior when the experimental design makes it difficult for $\mathrm{S}$ to discriminate the conditions of punishment from those of avoidance training..." Mowrer does state that the vicious circle effect is due to a failure of discrimination, but it is not the discrimination of punishment from avoidance training; rather, it is when Ss cannot discriminate between the starting and the shock areas of the runway that they get into and persist in the 'vicious circle' " (Mowrer, 1960, p. 487).

The empirical evidence from a number of studies (Melvin, 1964; Melvin \& Martin, in press) support Mowrer's conditioned fear hypothesis rather than the discrimination hypothesis considered by Smith et al. Certain conditions that produce facilitation in the vicious circle paradigm have been delineated (Brown et al, 1964; Melvin, Athey, \& Heasley, 1965); the phenomenon of facilitation as an effect of punishment has been found in at least seven studies during the last two years (e.g., Martin \& Melvin, 1964).

In fact, Martin (1965) found that punishment-induced facilitation tended to be an increasing function of shock intensity - a result diametrically opposed to that of Smith et al. The crucial difference is again the location of shock in the response sequence. It seems that such statements as "...facilitation of responding by punishment is the exception rather than the rule, and that the conditions which generate punishment-induced facilitation are as yet not delineated" (Smith et al, 1966, p. 271) are worded in too general a fashion. This statement should at least be qualified by the addition of a phrase such as "in an avoidance paradigm." Even this qualification is probably not sufficient at the present time, since reliable vicious circle behavior in a oneway avoidance paradigm has just been reported(Melvin \& Smith, 1966).

Thus, we cannot agree with Smith et al that their's was "... a setting designed to maximize the possibilities of obtaining facilitation during extinction." Another relevant study may be that of Whiteis (1956), who found the vicious circle effect in an avoidance situation. This behavior was disrupted, however, when a partition denoting the shock section of the runway was inserted. Thus the swinging door of Smith et al may have served to mark off the area near it as "dangerous" during punishment-extinction. Also, as Smith et al have noted, the act of pushing through a swinging door might have been a very salient cue for punishment.

The above analyses, as well as the data reported by Smith et al, are supported by the findings of two earlier studies (Imada, 1959; Kamin, 1959). Both Kamin and Imada used rats in a shuttle box, and both investigators reported that, in general, punishment inhibited avoidance behavior during extinction. While these studies are not methodologically identical to that of Smith et al, they 
seem at least as relevant as the lone empirical study of punishment cited by Smith et al (Solomon et al, 1953). This latter experiment showed punishment-induced facilitation in a "traumatic avoidance learning" paradigm. We tend to credit this facilitation to the interaction of intense shock with the species (dogs) rather than "overtraining" or Mowrer's (1960, p. 487) notion of "generalized discipline."

The parametric study of Smith et al (1965) provides valuable information on the effects of a punishment administered in a specific area ("near door') at the end of one type of avoidance response. The effects of punishment are, however, highly dependent on the context in which it is administered, and where it is applied in the response sequence. This has been emphasized by Solomon, who states that punishment "... is an event in a temporal and spatial flow of stimulation and behavior, and its effects will be produced by its temporal and spatial point of insertion in that flow" (1960, p. 242). Thus, generalizations relevant to its effects must be carefully qualified. We maintain that some conditions under which a certain type of punishment facilitates behavior have been delineated.

\section{References}

Brown, J. S., Martin, R. C., \& Morrow, M. W. Self-punitive behavior in the rat: Facilitative effects of punishment on resistance to extinction. J. comp. physiol. Psychol., 1964, 57, 127-133.

Brown, J. S., Anderson, D. C., \& Weiss, C. G. Self-punitive behavior under conditions of massed practice, J. comp. physiol. Psychol., 1965, 60, 451-453.
Church, R. M. The varied effects of punishment on behavior. Psychol. Rev., 1963, 70, 369-402.

Hurwitz, H. M. B. Vicious circle behaviour under two shock intensities. Brit. J. Psychol., 1961, 52, 377-383.

Imada, $\mathbf{H}$. The effects of punishment on avoidance behavior. Jap. psychol. Res., 1959, 1, 27-38.

Kamin, L. J. The delay of punishment gradient. J. comp. physiol. Psychol., 1959, 52, 434-437.

Martin, R. C., \& Melvin, K. B. Vicious circle behavior as a function of delay of punishment. Psychon. Sci., 1964, 1, 415-416.

Martin, R. C. Vicious circle behavior and escape conditioning as a function of intensity of punishment. (Doctoral dissertation, University of Florida) Ann Arbor, Mich.: University Microfilms, 1965, No. 65-5993.

Melvin, K. B. Escape learning and "vicious-circle" behavior as a function of percentage of reinforcement. J. comp. physiol. Psychol., 1964, 58, 248-251.

Melvin, K. B., Athey, G. K. Jr., \& Heasley, F. H. Effects of duration and delay of shock on self-punitive behavior in the rat. Psychol. Rep., 1965, 17, 107-112.

Melvin, K. B., \& Smith, F. H. Facilitative effects of punishment on avoidance behavior. Paper read at S.E.P.A., New Orleans, April, 1966.

Melvin, K. B., \& Martin, R. C. Facilitative effects of two modes of punishment on resistance to extinction. J. comp. physiol. Psychol, in press.

Mowrer, O. H. Learning theory and behavior. New York: Wiley, 1960.

Smith, N. F., Misanin, J. R., \& Campbell, B. A. Effect of punishment on extinction of an avoidance response: Facilitation or inhibition? Psychon. Sci., 1966, 4, 271-272.

Solomon, R. L., Kamin, L. J., \& Wynne, L. C. Traumatic avoidance learning: the outcomes of several extinction procedures with dogs. J. abnorm. soc. Psychol., 1953, 48, 291-302.

Solomon, R. L. Punishment. Amer. Psychologist, 1964, 19, 239-253.

Whiteis, U. E. Punishment's influence on fear and avoidance. Harv. Educ. Rev., 1956, 26, 360-373. 